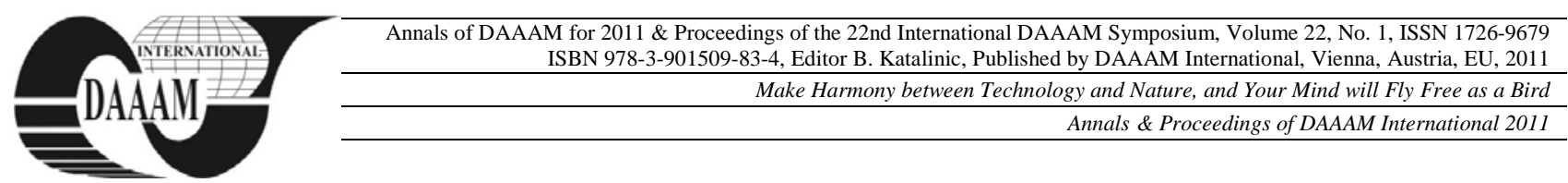

\title{
ASPECTS OF ENLARGEMENT OF THE PHOTOVOLTAIC SYSTEM- DE10
}

\author{
HRUSKA, F[rantisek]
}

\begin{abstract}
The interesting in photovoltaic as a source of renewable energy ask a new form of teaching and studying. The system $L A B I$ has very positive role in the field and has planed a emlargement of the real experimental model DE10 photovoltaic system. The experiment DE10 offers remote access for students and a professional community studying and testing the photovoltaic specifics without time, financial and other regression. The enlargement will content a new kind of photovoltaic panel, new parts of measurement loops, new possibility of client access via mobile devices. The using value of the DE10 is rising.
\end{abstract}

Key words: photovoltaic, photovoltaic system, remote access, measurement, automatic control

\section{INTRODUCTION}

Model DE10 of the system LABI (Hruska,2007; Hruska,2008; Hruska,2009) is a real laboratory system. The theme of DE10 is a photovoltaic system (Hruska,2010). There was utilized all priority and advantages of the system LABI: its openness, extending, remote accessing for students and people of professional community.

The model DE10 was testing and processing with positive results in a pilot processes and is used in standard regime now. After that there is came a idea to enlarge the system DE10 for new functions.

\section{DESCRIBING THE DE10 SYSTEM}

The experiment DE10 consists a modern and actual photovoltaic system. There are solved the specific problems of photovoltaic: automated tracking of the panel and changing the its position according to position of the sun during the day and year, manual setting of position for studying and testing the global radiation and efficiency of transfer sun irradiation on the electric energy. The using of the system is via the remote access over the Internet and manual processing. The scheme of the all system DE10 is in the fig.1.

The system contents: a track device for rotation in two axis, a set of end switches for azimuth and elevation position, potentiometric sensors of position , a sensor of sun irradiation, measurement of voltage and current of photovoltaic panel, sensors of temperature, moisture and other ambient parameters . The input system is connected to switch box. The switch box has located all transmitters, supplies and controlling computer accordant with protection again negative influencies. The main output is connected to the Internet.

The system DE10 was opening and testing according to technology and system during two years.

Main parameters of the experiment equipment DE10 are:

- $\quad$ Photovoltaic panel of ype STR 36-55, produced by Solartec CZ,
- $\quad$ Nominal/pick to pick power 55W,nominal voltage $12 \mathrm{~V}$, optimal voltage $17,6 \mathrm{~V}$, max. voltage $21,6 \mathrm{~V}$, short current 3,42A, optimal current 3,13A

- $\quad$ Proportion 0,991 m length/ 0,451 m width/0,034 m thickness, weight $5,5 \mathrm{~kg}$

Technology monocrystalic $\mathrm{Si}$

- $\quad$ Cover IP 54 , operation temperature from $-35^{\circ} \mathrm{C}$ to +85 ${ }^{\circ} \mathrm{C}$.

- $\quad$ Track system has 2 pieces of step motors a gears with 20Nm power unit of control impulses, range of azimuth position: $0^{\circ}$ až $180^{\circ}$; range of elevation position: $0^{\circ}$ (vertical position to surface of earth) up to $90^{\circ}$ (horizontal position to surface of earth).

- $\quad$ Measuring system: temperature and moisture of ambient (range -25 up to $50^{\circ} \mathrm{C}, 10-98 \%$ rel. moisture, output 4-20 $\mathrm{mA}$ ), irradiation(up to $100 \mathrm{kLux}$, output 4-20 mA), position of azimuth a elevation with potentiometers, range up to $270^{\circ}$, output $0-100 \Omega$,

- $\quad$ Industrial PC, type DataLab/PC with interface, unit of inputs and outputs, type Datalab_I/O.

The current results are positive. There were obtained the positive experience:

- Mechanical part: is satisfactory, robust, resistance to outdoor condition, good protection again rain, temperature and moisture.

- Electrical part: function of step motors is without any problems, the end switch needed to change at the test beginning and new practices without problems.

- $\quad$ System part: the central unit has been running without any collision.

- $\quad$ Measuring sensors show out $100 \%$ functionality, all tests of accuracy were positive.

The software of local application DE10 has been working with full functionality, without mistakes.

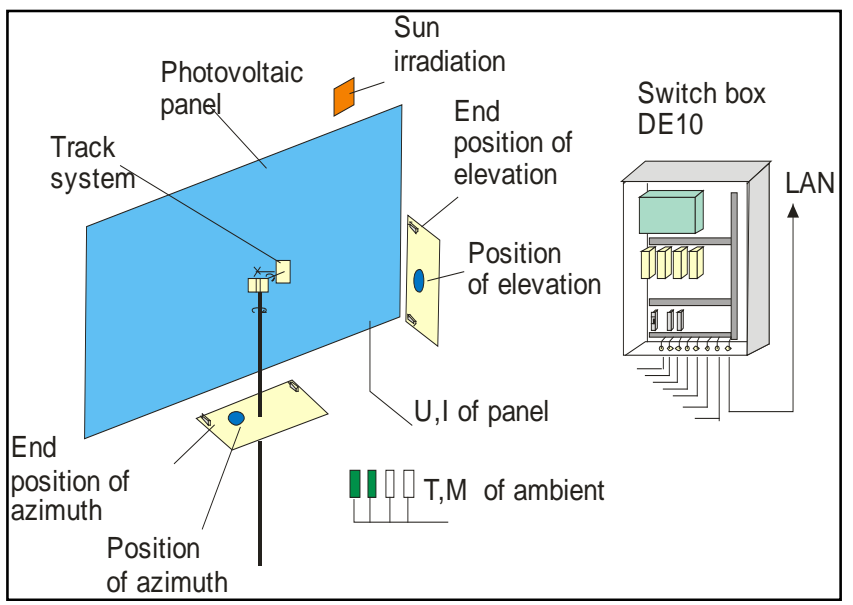

Fig. 1. Scheme of system DE10 - photovoltaic system 


\section{IDEA OF ENLARGEMENT OF DE10}

Experiences of pilot operation of DE10 have showed some possibility and given ideas to enlargement and improvement of current functions. They are at the moment:

1. The construction of DE10 is prepared as open to enlargement the kinds and areas of panels. There are discussed the possibilities of expand on new plastics panels and on panels with contractors.

2. The new project solves expanding on measurement of air quality in environment: $\left(\mathrm{CO}_{2}\right.$, ozone, $\mathrm{NO}_{\mathrm{x}}, \mathrm{CO}$, eventual VOC, wind speed and direction).

3. The new access to DE 10 and LABI will access from new mobile phones too. The application SW of DE10 and server's SW will have new html server program.

The scheme of project of hardware enlargement and function improvement is in fig. 2

The current photovoltaic panel (old in fig.) of monocrystalic technology is added the photovoltaic panel of polycrystalic technology (new in fig.). The measurement of light irradiation is added the equipment of global sun irradiation measurement. The measurement of environment quality is added the measurement of $\mathrm{CO}_{2}$, ozone, $\mathrm{NO}_{\mathrm{x}}, \mathrm{CO}$, eventual VOC, wind speed and direction. There will applied some modern electrochemical sensors and special sensors for speed and direction of wirn by ultrasonic principles.

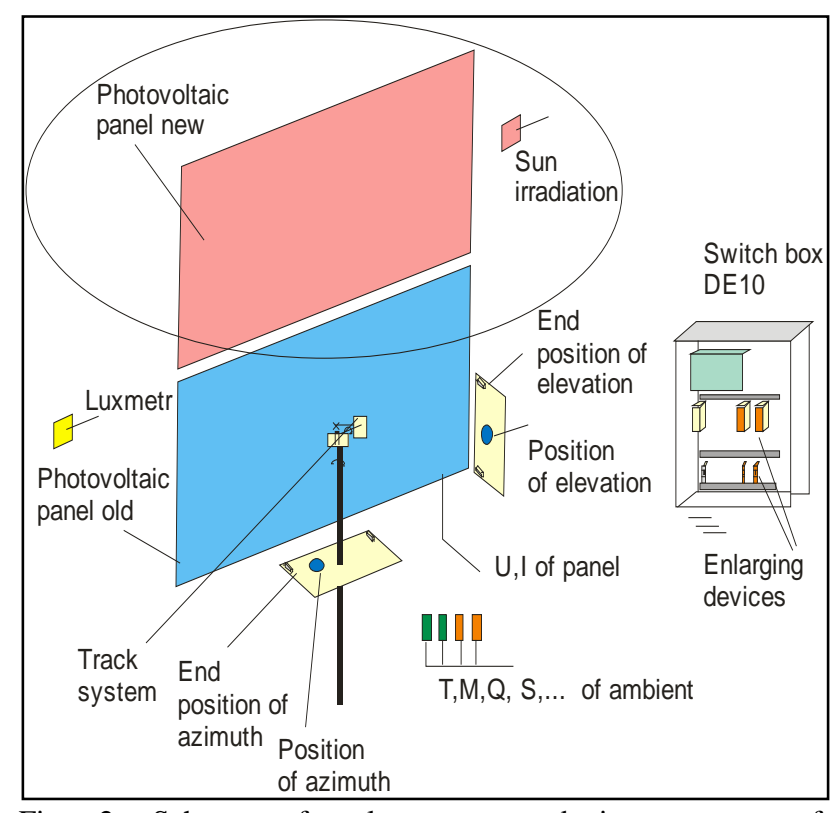

Fig. 2. Scheme of enlargement and improvement of photovoltaic system DE10

The electronic circuits, transmeters are installed in the free area of switch box DE10. The output signals are connected to input/outpur units of central unit DataLab.

\section{ASPECTS OF ENLARGEMENT OF DE10}

The first aspect is using a new photovoltaic panel with other principles. The goals is given possibility to test end learn two principles and their energy efficiency of interested person.

There is planed to use as the new panel (top panel in fig 6) polycrysstalic or panel with concentraded cells. The vizualisation the process of both panels is in data table showed in fig. 3. In the table there are all data for old (panel a) and new (panel b) visualized. The date are direct evaluated, written in the table and graph and in the archive files.

The second aspect is adding some new sensors to measure outdoor environment. The current measuring points (temperature and moisture of outdoor air) are enlarged a measurement the concentration of $\mathrm{CO}_{2}$ of outdoor air, active oxygen, $\mathrm{NO}_{\mathrm{x}}$ or radioactivity of environment background and other parameters.

The thirth aspect is developing a new software for client and server station. The asking is to have all data better visualized and to have as a client a PDA unit too.

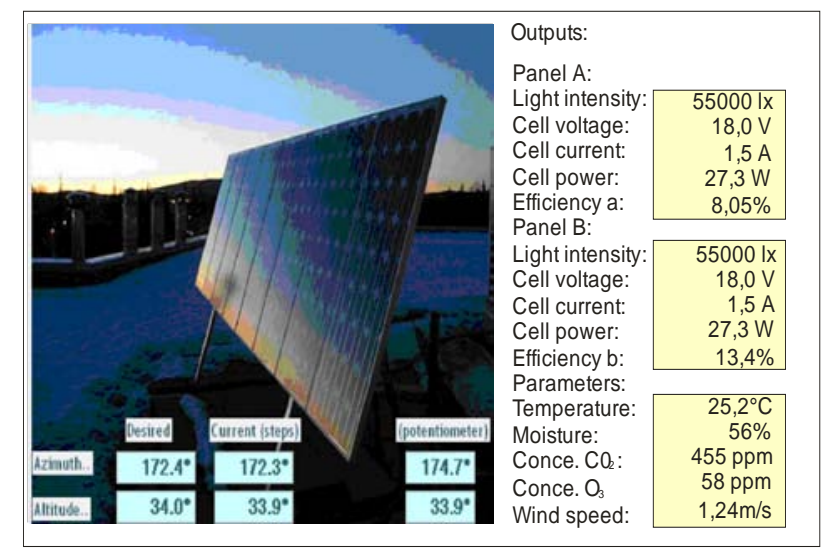

Fig. 3. Scheme of enlargement and improvement of photovoltaic system DE10

\section{CONCLUSION}

The experiences of pilot operation confirm operating, functionality and signification of system DE10 at the period 6 months and so it can make the enlargement the DE10 system. The new aspects are doing the more excellent system with greater extent. The two different photovoltaics panels give possibility to test and learn new photovoltaics technologies. They can give us some information in energy efficience and economic efficience too.

The date of environment by their continued saving are the base to study the running processes during day and more in the environment.

How is next father development or research? The construction of DE10 is very hard and could have more as two panels. Next very intensive development work can be in the field mathematical evaluation the data of environment.

\section{ACKNOWLEDGEMENTS}

This work was supported in part by the Ministry of Education, Youth and Sports of the Czech Republic under grant No. MSM 7088352102: "Modeling and control of processes of natural and synthetic polymers".

\section{REFERENCES}

Hruška,F. (2007) Internet a laboratoře integrované automatizace (The Internet and the Integrated Automation Laboratory). Jemná mechanika a optika, 2, 2007, pp.64-66. ISSN 0447-6441

Hruška F. (2008) Experimental Model of Photovolataic Systems. Proceedings of the 12th International Research/Expert Conference "Trends in the Development of Machinery and Associated Technology” TMT 2008, 26.30.82008, Istanbul, Turkey, ISBN 978-9958-617-41-6, pp. 645-648, Istanbul Univerzity, Instabul

Hruška F. (2009) Experimental Photovolataic System. Proceedings of the 20th International DAAAM Symposium "Intelligent Manufactoring \&Automation” DAAAM 2009, 25-28.11.2009, Vienna, Austria, ISBN 978-3-901509-70-4, pp. 923-924, DAAAM International, Vienna

Hruška F. (2010) Photovoltaic System in System LABI. Proceedings of the 14th WSEAS International Conference on Systems "Latest Trends on Systems", (Part of the 14th WSEAS CSCC Multiconference), 22-24.7.2010, Corfu, Greece, ISBN 978-960-474-214-1, pp. 498-499, WSEAS Press, Corfu 